\title{
Enhancing Students' Cooperative Learning in an EFL Classroom through Lesson Study
}

\author{
Titi Wahyukti \\ English Education Department \\ Universitas Muahammadiyah Purwokerto \\ Purwokerto, Indonesia \\ titiwahyukti@yahoo.co.id
}

\begin{abstract}
Learning English in an EFL classroom demands the students to learn it as both material and classroom instruction. English for most EFL students is considered difficult especially when they use it as a means of communication. Since English becomes a challenge to discuss, it makes most students feel afraid of cooperating and collaborating in learning processes. A fact showed that a big number of students were reluctant to do group discussion. A five-cycled open lesson has already conducted as an effort to solve the students' problems. During the five cycles of Lesson Study, the students were asked to discuss the material of Teaching English as a Foreign Language and present the result of their discussion in front of other groups. The targets of the LS are: (1) enhancing students' cooperative learning activities during discussion, and (2) making the students accustomed to group discussion and material presentation. Firstly, the students were still confused in conducting group discussion. Most of them did not know what they had to do and felt unmotivated in using English as a medium of communication. As a result, most groups were dominated by particular students. A lesson study -based action was taken, individual works which then support the group discussion result was given to the students. No one in the group was silent and neglected. Each student had the same responsibility to fulfill the task. Consequently, all of the students contributed to the group activity. In short, the students were motivated to do group discussion through cooperative learning.
\end{abstract}

Keywords : A foreign language learning, cooperative learning, lesson study

\section{Introduction}

College students especially who study in English Education department need to learn English as the language learning material and also as a medium of instruction. As a foreign language, English is not commonly used in oral communication outside of the students 'area but is widely found in written texts such as in newspapers, magazines, commerce, internet and other sources because English is an international language which is used all over the world. Therefore the university students have to practice using it when they want to be able to communicate with people of foreign countries in order to access knowledge and information from oversees. Since English becomes a challenging language to study, it makes most EFL students think it difficult as English in many ways is quite different from their native language. In EFL classroom the students lack confidence of using English properly, they try rarely to promote questions or give remarks on a learning material given by a teacher. This might be caused the teaching learning process mostly uses teacher-centered learning methods in which the role of teachers/lecturers is dominant, resulting in less autonomy for students. It can be seen from the low student-teacher interaction in the classroom, especially when there are some problems/questions which students need to ask or discuss with lecturers. Students tend to be silent such as because they do not understand the issued material or what to ask. Once it was shown by the fact that a great number of the students tended to keep silent and just listen to teacher's material presentation in teaching learning process; and teacher's questions were not rapidly responded until the students were encouraged to give an answer. Such a problem should be addressed, so that the quality of the learning process in which students' real engagement is improved. This might be solved by 
implementing group discussion and cooperative learning in the teaching and learning process. In group discussion, group members get involved in doing a task and help each other in achieving a goal through supportive interaction in their environment.

The learning process in the classroom at schools or colleges should be done in a way that is interactive, fun, motivating students to participate actively. The learning process should also provide time and space for creativity and autonomy in accordance with students' talents, interests and their psychological development. In other words, to constitute interactive learning community among students, cooperative learning model should be applied in order to motivate students to be active, creative participants.

Cooperative learning and English foriegn language students go together. A cooperative learning promotes English language acquisition among EFL students by helping them become more confident in producing and using English when working in small groups, and students are able to pick up new learning methods by observing how their peers solve problems that involve learning English. Cooperative learning model is applied in almost all school areas and increasingly in college and university contexts and is claimed to be an effective teaching method in foreign/second language education (Johnson \& Johnson, 1989; Kessler, 1992). The implementation of Cooperative learning in EFL students is collaboratively done with colleagues through Lesson Study (LS) in five cycles. The purposes of this study are: (1) enhancing students' cooperation during group discussion, and (2) making the students accustomed to mterial presentation in good English.

\section{Cooperative Learning for EFL students.}

Teaching methodology of English as a foreign or second language provides students with the didactic-pedagogical and psycholinguistic knowledge to develop concepts for innovative teaching. Good teaching methods are those which can encourage students to learn. It is also viewed that good learning employs multiple methods or techniques, which support each other. On the other hand some the appropriateness of methods depends on the objective, content and activities of teaching and learning and then the media which can support the learning process. Group learning has traditionally been a part of educational practice. Its effectiveness has been proved through a lot of research studies in different countries (Johnson \& Johnson, 1986). Consequently cooperative learning is now widely recognized as one of the most promising practices in the field of education so as to learning English as a foreign language.

Cooperative learning might be defined in different ways. One of the definitions is that cooperative learning is a system of teaching and learning techniques in which students are active agents in the process of learning instead of passive receivers of any given knowledge. This system could increase the students' activeness as well as personal development. Cooperative learning activities might reduce students' learning anxiety, increase the amount of student participation as well as students talk in the target language. Beside that it is also supportive and less threatening learning environment. Kagan (1995) also claimed that communicative language teaching and cooperative learning were natural match in foreign language teaching.

Cooperative learning is an organized and structured way to use small groups to enhance student learning and interdependence. In this study cooperative learning was implemented through group discussion. A group of six-to-eight students was given a task, better known as an assignment, and group members worked together to accomplish this task. Each individual of the group had responsibilities and was held accountable for aiding in the completion of assignment. Finally they presented it as the result of group discussion in front of the class to the whole members of class. Therefore success of doing the task was dependent on the work of everyone in the group. In addition to learning from each other, students also learned how to work as part of a team and had others depend on them. An investigation revealed that cooperative learning had a positive impact on almost all of the factors to language learning. In general, cooperative learning 
covered four basic principles that made it successful in delivering material (Kagan, 1994); they were called : positive interdependence, individual accountability, equal participation, simultaneous interaction and social skills

In relation to positive interdependence, it was a sense of working together for a assigned task and caring about each other' learning. Students were placed on the same side, they should do the assignment hand in hand. Within cooperative learning condition, students had to ensure that all members of the group learned the assigned material and each of them was responsible to complete the task with a help from the others. When positive interdependence was clearly understood, each member of the group was required to give a unique contribution to make the joint effort for group success.

The second principle was individual accountability which provided for each member believing that it was important for her/him to learn the material. Each team member had responsibility of their own and their teammates' learning and made an active constribution to the group. To satisfy the principle of individual accountability, students must perform on their own task to accomplish the group assignment. A teacher must have a way of determining what each individual had learned as well as what the group had accomplished.

The third principle was equal participation. When cooperative learning was applied, the students were provided abundant verbal, face-to-face interaction in which they discussed, explained, argued and linked the learning material with what they had learned previously. The interaction among the students was carefully designed so there was no member feeling free from doing the task. Each group member should be actively involved as each of them had equal participation to give a real contribution on doing the assignment, then there was no one member who did most (or all) of the work.

The last principle was simultaneous interaction and social skills. In making group discussion, students needed to be clustered together in a tight group, facing each other in order to have the kind of interchange necessary to accomplish the task. A group discussion provided a great chance of students' talking time. In a group of six students there were six participants practicing language; within thirty students in the class the participation of group discussion increased significantly because simultaneous interaction between students of various abilities and background gave more students' talking time. It was important for the students to have sufficient social skills involving learning of communication, trust and conflict resolution skills so that they could cooperate effectively.

Through cooperative group discussion, the students were trained to express their ideas to other members and to respect the opinion of others. Thus it would be beneficial for both sides for those who have high or low abilities. Those who have low skills would be assisted as they interact with having higher skills. On the other hand those who have higher skills would feel satisfied as they could help their peers.

\section{Lesson Study for Language Teaching}

Lesson study derives from a Japanese word jugyokenkyu, which means a systematic process used by Japanese teachers to examine the effectiveness of their teaching to improve the students' engagement in teaching learning process and the learning outcome. Each cycle of lesson study (LS) is implemented in three stages which are planning, doing and seeing/reflecting. In LS, there are at least two teachers who perform as a teacher model and a teacher collaborator. They usually meet together regularly to design collaboratively the teaching material and its learning media with the chosen technique which is done in the classroom. After designing a lesson plan, the teacher model implement it in the classroom and the collaborator observes the activity of students during teaching learning process. Finally they do reflection and discussion on the observed lesson to get some feedback to improve instruction.

In this study LS was implemented in five cycles in one semester, which involved one teacher model and two teacher collaborators. 
The focus of this LS was to make students able to improve their learning quality to achieve good outcome through cooperative learning. By using this method, students were provided some activities to work in groups and able to develop both their knowledge and communication ability among the class members.

The principle of LS coincide with the idea that learning is a social and situated process; and for teachers, they can improve their teaching instruction in the classroom. Some benefits can be taken from the implementation of LS for the teacher model, teacher collaborators and mostly for the students. Through LS, the teacher model can explore and develop creativity in teaching, especially in implementing the teaching techniques and strategies and the way how to motivate the students to learn in order to do the best of their study. In the other hand for the teacher collaborators, they can make a good use of their observation. They get some experiences and knowledge how to teach with different ways. Trough observation, they can see some strengths and weeknesses of a certain action in teaching learning process in the classroom that can be discussed in doing reflection. Moreover, this collaborative team work make them able to select the appropriate learning and teaching strategies. The other benefit is addressed to students; they have some experiences in doing collaborative learning, as mentioned before. The students could help hand in a hand with the other members in groups to comprehend the learning material and make personal interaction in using the language. They would be the active participants to accomplish group assignment; they are able to interactive with group members and appreciate the others' existence to be autonomous learners. As a whole, students find their way to build social and collaborative communication with others.

\section{Conclusion.}

Based on this study, specifically in cooperative learning context, there were many interactive tasks that naturally improved the students' knowledge, language use and social interaction skills. The implementation of LS in
EFL classroom in this study was designed by applying cooperative learning activities. Cooperative activities tended to integrate the study of learning material, the language use in communication and create powerful learning opportunities. The findings that supported the questions in this study favored cooperative learning as a powerful instructional method to enhance the students' cooperation in terms of positive interdependence, individual accountability, equal participation, simultaneous interaction and social skills. In a group discussion, team members were assigned to present the material and communicate the discussed subject to the class members in good English. Thus, cooperative learning could achieve the positive effects in language acquisition as well as enhancing motivation toward learning English. Likewise, the lowcompetence and high-competence students might be hand in hand to display their oral performance. Taken as a whole, the findings of this study revealed some advantages for English language classroom, namely, group work generated interactive language, promoted students' responsibility and autonomy and also group work could be used for individualized instructions.

\section{References}

Brown, H. Douglas. (2001). Teaching by Principles: An interactive approach to language pedagogy (2nd ed). NY : Prentice Hall Regents

Gutierez, Sally Baricaua. (2015). Collaborative Professional learning through Lesson Study: Identifying the Challenges of Inquiry-based teaching. Journal in Educational Research. Available on line at Http://www.iier.org.au/iier 25/gutierez.pdf. accessed on 5 September 2017.

Johnson, D,\& Johnson, R. (1989). Cooperative and Competition: Theory and research. Edina, MN: Interaction Book Company.

Kagan, Spencer. (1994).Cooperative Learning. San Clements, CA : Kagan Publishing.

Kagan, S, Kagan, M. \& Kagan, L. (2000) Reaching English/Language Arts Standards through Cooperative Learning: Providing for ALL Learners in General 
Education Classroom. San Clemente, CA: Kagan Publishing.

Manabu, Sato.2015. Lesson Study for Learning Community (Lecture Material. Tokyo: JICA

Marsono. (2016). Development of a Cooperative Micro Lesson Study Learning Model to teaching creatively and teaching for the creativity of engineering students. Journal : World Transactions on Engineering and Technology Education. Vol.14. No.2. available online at www.wiete.com.au/journal/WTE\&ET../15Marsono.pdf. Accessed 31 Agustus 2017 